\title{
Kinetic Study of the Reaction of Diborane with Phosphine*
}

\author{
H. Brumbergert and R. A. Marcus \\ Department of Chemistry, The Polytechnic Instilute of Brooklyn, Brooklyn, New York
}

(Received May 27, 1955)

\begin{abstract}
The homogeneous gas phase reaction between diborane and phosphine at $0^{\circ} \mathrm{C}$, yielding a solid product of composition $\mathrm{BH}_{3} \mathrm{PH}_{3}$, has been observed to give a linear relation between the initial rate of reaction and the pressure of either reactant, provided a certain pressure of each reactant, determined by the equilibrium constant and the pressure of the other gas, is exceeded. The reaction rate is independent of the amount of surface of the solid product or of the wall. When either reagent is in appreciable excess, the rate-time data obey a pseudo first-order equation.

These facts are consistent with a rate-controlling reaction of diborane with phosphine to give $\mathrm{BH}_{3} \mathrm{PH}_{3}$ and $\mathrm{BH}_{3}$, the borine reacting further with phosphine, and the $\mathrm{BH}_{3} \mathrm{PH}_{3}$ condensing rapidly to a solid. This mechanism leads to a rate equation which is in good agreement with the experimental evidence. The activation energy of the rate-controlling step is $11.4 \pm 2.0 \mathrm{kcal} \mathrm{mole}^{-1}$.
\end{abstract}

\section{INTRODUCTION}

$\mathbf{R}$ ECENTLY, a number of kinetic studies of reactions of diborane have appeared. ${ }^{1}$ In each case the postulated mechanism involved an initial split of the diborane into borine fragments, followed by a reaction of the borine "radical" with one of the reactants. The apparent activation energy of each reaction included contributions from various elementary steps. While the heat of dissociation of diborane could not be estimated from the temperature coefficient of these rate studies, an upper limit for this value could be set in each case. For example, the activation energy for the isotopic exchange reaction of diborane with deuterium is $20.4 \pm 2 \mathrm{kcal} \mathrm{mole}^{-1}$. From an analysis ${ }^{2}$ of the data on this reaction it can be inferred that an upper limit for the dissociation energy is $41 \mathrm{kcal}$ mole $^{-1}$. In general, the lower the temperature at which the reaction occurs easily, the lower the estimated value of the upper limit.

It appeared that a study of the reaction of diborane with phosphine might give further information on this question. This reaction was found ${ }^{3}$ to occur readily at $0^{\circ} \mathrm{C}$, a temperature lower than that of the previously mentioned kinetic studies. The product is a white, crystalline material of composition $\mathrm{BH}_{3} \mathrm{PH}_{3}$ which

* This work was done under Contract No. Nonr 839(09), Project No. NR 051-339 between the Office of Naval Research and the Polytechnic Institute of Brooklyn.

† From a dissertation presented by Mr. Brumberger in partial fulfillment of the requirements for the $\mathrm{Ph} . \mathrm{D}$. degree at the Polytechnic Institute of Brooklyn, 1955. Present address: Department of Chemistry, Cornell University, Ithaca, New York.

${ }^{1}$ Bragg, McCarty, and Norton, J. Am. Chem. Soc. 73, 2134 (1951); R. P. Clarke and R. N. Pease, ibid., 73, 2132 (1951); H. G. Weiss and I. Shapiro, ibid., 75, 1221 (1953); P. C. Maybury and W. S. Koski, J. Chem. Phys. 21,742 (1953); A. T. Whatley and R. N. Pease, J. Am. Chem. Soc. 76, 835 (1954).

2 See R. A. Marcus, J. Chem. Phys. 23, 1107 (1955). From Eq. (15) of that paper the activation energy is, according to the mechanism discussed, the activation energy of the reaction of borine with diborane plus one-half the heat of dissociation of diborane. The minimum value for the former contribution is, of course, zero, so that the value given here for the upper limit follows.

${ }^{3}$ E. L. Gamble and P. Gilmont, J. Am. Chem. Soc. 62, 717 (1940). dissociates reversibly into the reactants. The kinetics of this reaction have not been previously examined. If a preliminary split of the diborane into borines occurs in this reaction, the relative rapidity of the over-all process would presumably indicate that the activation energy for the subsequent recombination of borine with phosphine is appreciably lower than that for its reaction with various other ${ }^{1}$ compounds. The activation energy of the over-all reaction might then be used to obtain a reasonable approximation to the heat of dissociation of diborane. The present study was undertaken to see whether this or a different mechanism prevailed in the diborane-phosphine reaction.

\section{EXPERIMENTAL}

\section{Materials}

Diborane was prepared by the action of boron trichloride on ether solutions of lithium aluminum hydride, ${ }^{4}$ then purified by repeated distillation from traps at $-78^{\circ} \mathrm{C}$ through traps at $-113^{\circ} \mathrm{C}$ (the temperature of a carbon disulfide slush) into a storage vessel kept at $-196^{\circ} \mathrm{C}$; the gas was freed of accumulated hydrogen by pumping at $-196^{\circ} \mathrm{C}$. Phosphine was prepared by the reaction of calcium phosphide with water, purified by distillation through three traps at $-78^{\circ} \mathrm{C}$, degassed of hydrogen by pumping at $-196^{\circ} \mathrm{C}$, and stored over phosphorus pentoxide. Only small amounts of noncondensible gases accumulated in the storage vessels for the diborane and phosphine over long periods of time.

\section{Apparatus}

The course of the reaction of diborane with the phosphine was followed by observing changes in the total pressure with time, using a capillary mercury manometer. The system employed for handling the gases was a standard high-vacuum apparatus and included a reaction vessel of approximately $40 \mathrm{cc}$ volume, a diffusion pump, a McLeod gauge, and a

\footnotetext{
'Finholt, Bond, and Schlesinger, J. Am. Chem. Soc. 69, 1199
} (1947). 
gas burette. Stopcocks rather than mercury cutoffs were used throughout the system; contact of diborane with stopcock grease, Apiezon $\mathrm{N}$, over periods of three to eleven hours (the times required for various runs) did not seem to have any deleterious effect.

The temperature of the reaction vessel was controlled by immersion, respectively, in an ice-water bath $\left(0.0^{\circ} \mathrm{C}\right)$, an ethylene glycol slush $\left(-13.2^{\circ} \mathrm{C}\right)$, and a slush of technical grade carbon tetrachloride $\left(-23.7^{\circ} \mathrm{C}\right)$. The temperature control was within $\pm 0.1^{\circ} \mathrm{C}$.

Because the reaction product has a very high dissociation pressure ${ }^{3}\left(1400 \mathrm{~mm}\right.$ at $\left.25^{\circ} \mathrm{C}\right)$, it was possible to distill both materials into the reaction vessel from the gas burette, warm the gases to room temperature, and then commence the run by immersing the vessel in the appropriate cooling bath. Further, it was found possible to reuse the starting materials by simply allowing the product to dissociate into stoichiometric quantities of diborane and phosphine by warming to room temperature.

Some experiments were also performed in a different apparatus, to estimate the amount of $\mathrm{BH}_{3} \mathrm{PH}_{3}$ present in the gas phase in these systems. The reaction vessel for these experiments was such as to permit precise pressure measurements. It consisted of a 250 -cc volume bulb, attached with narrow tubing to a wide bore U-tube manometer. The height of the mercury in each of the arms of the manometer was read with a precision of $0.01 \mathrm{~cm}$ using a cathetometer. The mercury level could be adjusted so that the reaction vessel had the same volume during each pressure measurement. The reaction vessel was kept at $0^{\circ} \mathrm{C}$ during these measure.

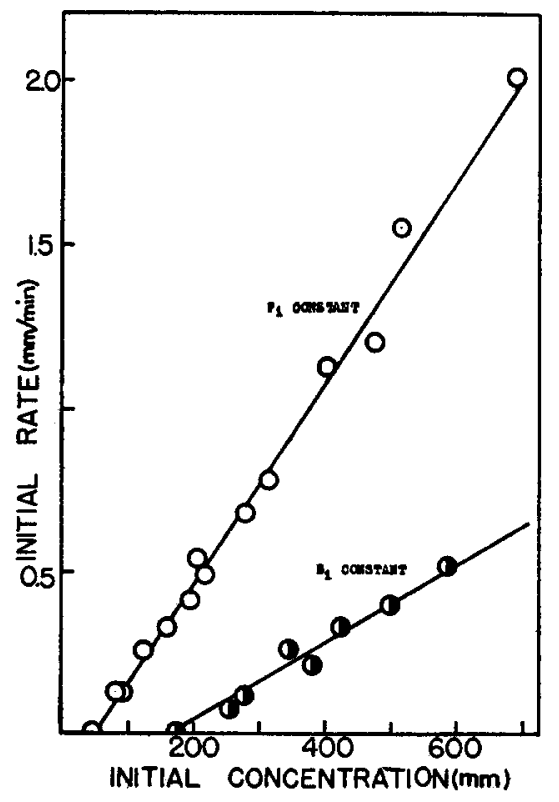

FIG. 1. Plot of initial rates vs initial pressures at $0^{\circ} \mathrm{C}$. $\mathrm{O}=$ initial phosphine pressure has the constant value, $158.5 \pm 2.0 \mathrm{~mm}$ $0=$ initial diborane pressure has the constant value, $39.0 \pm 0.5$ $\mathrm{mm}$. ments. Only a small fraction of the system was exposed to room temperature.

\section{RESULTS}

At temperatures where the reaction is conveniently studied (near $0^{\circ} \mathrm{C}$ ), the dissociation pressure of the product is large and the back reaction therefore appreciable. An estimate of the amount of gaseous $\mathrm{BH}_{3} \mathrm{PH}_{3}$ present in these systems was made from the following experiment. ${ }^{5}$ Known amounts of approximately stoichiometric gaseous reactants were mixed such that the total pressure was slightly less than the dissociation pressure and, consequently, such that no solid product could be formed. The formation of some gaseous addition compound would cause the total pressure to be less than the sum of the initial pressures of the reactants. One of the reactants was first dosed into the reaction vessel and, after recording its pressure at $0^{\circ} \mathrm{C}$, it was stored in an isolated trap. The other reactant was then admitted to the vessel and its pressure at $0^{\circ} \mathrm{C}$ determined. Finally, the original gas was recondensed into the reaction system and the total pressure at $0^{\circ} \mathrm{C}$ noted for periods up to several hours. As mentioned in the previous section, the volume

TABLE I. Extent of formation of gaseous addition compound.

\begin{tabular}{cccc}
\hline \hline $\begin{array}{c}\mathrm{B}_{2} \mathrm{H}_{6} \\
(\mathrm{~mm})\end{array}$ & $\begin{array}{c}\mathrm{PH}_{3} \\
(\mathrm{~mm})\end{array}$ & $\begin{array}{c}\text { pobs } \\
(\mathrm{mm})\end{array}$ & $\begin{array}{c}\Delta^{\mathrm{a}} \\
(\mathrm{mm})\end{array}$ \\
\hline 58.9 & 118.0 & 174.2 & -2.7 \\
58.5 & 117.5 & 173.5 & -2.5 \\
\hline
\end{tabular}

$\Delta$ is the difference between the observed total pressure pob, and the sum of the first and second columns.

of the reaction system was the same for each pressure measurement. The results are given in Table I.

From the last column in Table $I$ it is seen that the difference between the observed total pressure and the sum of the initial pressures of the reactants is small, about one percent. This may reflect the presence of a small amount of gaseous addition compound, or the presence of a small amount of reactive impurity. In any case, the gaseous addition compound is present only to a slight extent, and it is this fact which will be used in relating the pressure measurements of the kinetic experiments to a reaction rate. The use of higher pressures of the reactants will increase somewhat the percent of material present as addition compound. However, it can be concluded that under the conditions employed in the present kinetic experiments in order to obtain solid product, there is only a very small amount of gaseous compound formed. This means that during the course of reaction there is a simple relation between the partial pressures of the reactants and the total pressure: to a very good degree of approximation the change in phosphine pressure is two-thirds, and

${ }^{5} \mathrm{We}$ are indebted for these results to Mr. E. Helfand who, working in these laboratories, obtained the data given in Table I. 
the change in diborane pressure is one-third of the change in total pressure at any reaction time.

It is seen from these experiments that if a constant initial pressure of diborane is maintained in a series of runs, the reaction will not start until a certain pressure of phosphine, determined by the initial diborane pressure and the equilibrium constant, is exceeded. The initial rate of pressure decrease was then found to vary linearly with the increasing initial phosphine pressure, $P_{i}$. Similarly, for a series of runs with a given initial phosphine pressure, the initial rate was zero until a definite diborane pressure, determined by $\mathrm{P}_{i}$ and the equilibrium constant, was exceeded, and was then observed to increase linearly with increasing $\mathrm{B}_{i}$, the initial diborane pressure. These data are shown in Fig. 1. The initial rates were obtained by linear extrapolation of the experimental pressure-time curves to zero time. ${ }^{6}$

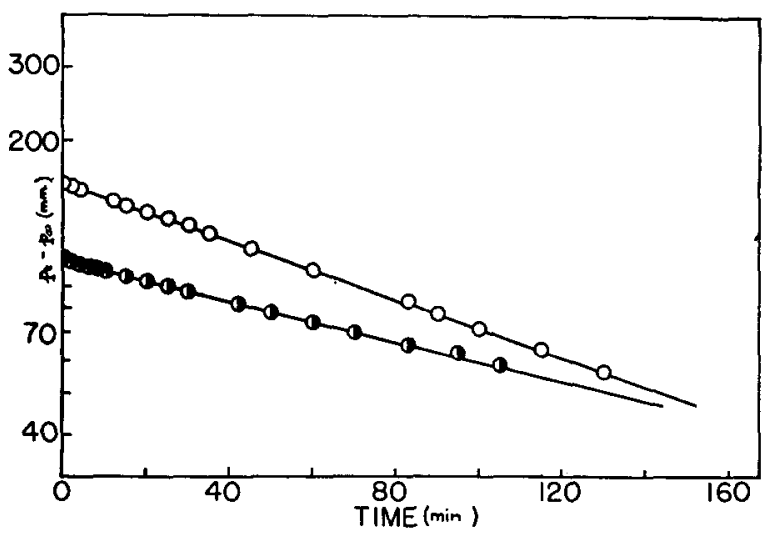

FIG. 2. Semilogarithmic plot of $p_{t}-p_{\infty}$ vs $t$. Both runs have been carried to more than $70 \%$ completion. $\mathrm{O}=$ diborane in excess, initial pressures of phosphine and of diborane were $157 \mathrm{~mm}$ and $480 \mathrm{~mm}$ respectively. 0 phosphine in excess, the initial pressures of the two reactants being 585 and $39 \mathrm{~mm}$. The reaction temperature was $0^{\circ} \mathrm{C}$.

The equilibrium constant at $0^{\circ} \mathrm{C}$ was determined by allowing measured quantities of diborane and phosphine to react until no pressure change was observed over periods of several hours. The equilibrium constant $\mathrm{K}_{e}$ was calculated from the equation

$$
\mathrm{K}_{\varepsilon}=\left(\mathrm{B}_{i}-\frac{1}{3} \Delta p\right)\left(\mathrm{P}_{i}-\frac{2}{3} \Delta p\right)^{2},
$$

where $\Delta p$ denotes the total pressure drop, and $\mathrm{B}_{i}$ and $\mathrm{P}_{i}$ denote the initial pressures of the diborane and

\footnotetext{
${ }^{6}$ Data obtained in the first five minutes were not used in the estimation of these initial rates. This introduced but little error since the half-time of the reaction was generally of the order of several hours. Blank experiments using one reactant at a time showed that the time required to establish thermal equilibrium was only about $0.5 \mathrm{~min}$. However, the extent of pressure decrease during the next five minutes was about 1-2 mm greater than that expected on the basis of the subsequent rate of pressure decrease. This initial behavior may represent the time required to build up a steady state of the small amount of gaseous addition compound present, or it may represent the presence and rapid reaction of about one percent impurity. In any case it did not particularly interfere with the initial rate determinations.
}

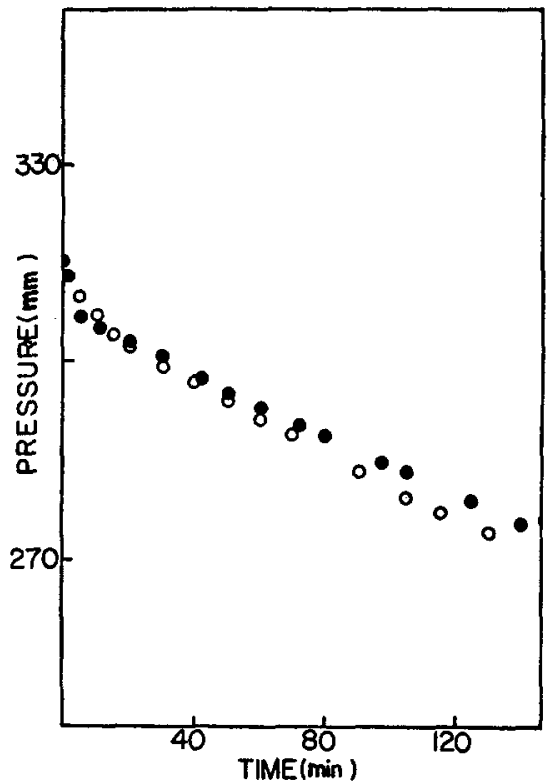

FIG. 3. Plot of total pressure vs time at $0^{\circ} \mathrm{C}$; effect of increased glass surface: $\bullet=$ no glass wool. $O=$ Pyrex glass wool.

phosphine, respectively. Equilibrium was approached from both sides in each experiment. An average value of $1.14 \pm 0.13 \times 10^{6} \mathrm{~mm}^{3}$ was obtained for $\mathrm{K}_{e}$ at $0^{\circ} \mathrm{C}$.

When $\log \left(p_{t}-p_{\infty}\right)$ was plotted against $t$ for several experiments with a large excess of one reactant (where $p_{t}$ is the total pressure at time $t$, and $p_{\infty}$ is the total equilibrium pressure), very good first-order curves were obtained (Fig. 2).

A number of experiments were performed to determine the dependence of the reaction rate on surface area. To determine the effect of increasing the wall area, experiments were made in the reaction vessel filled with enough glass wool to increase the superficial surface area by a factor of forty while leaving the reaction volume effectively unaltered. The results are given in Fig. 3. Only a very small effect on the rate is seen to occur.

The influence of the surface area of solid product on the rate of reaction at $0^{\circ} \mathrm{C}$ was investigated by making a series of experiments with stoichiometric quantities of diborane and phosphine, at three different initial total pressures. Thus, corresponding points could be found on each pressure-time curve at which the pressures were the same but the amount of solid different. Figure 4 shows that the reaction rate (given by the tangent to the pressure-time curve) is the same for the same total pressures, regardless of the differing amounts of solid surface present.

The conclusion that the reaction rate is independent of the quantity of solid present was corroborated by preliminary studies of the rate of dissociation of the solid at $0.0^{\circ} \mathrm{C}$, which indicated that this rate is independent of the initially present quantity of solid $\mathrm{BH}_{3} \mathrm{PH}_{3}$.

An activation energy was determined from a series 


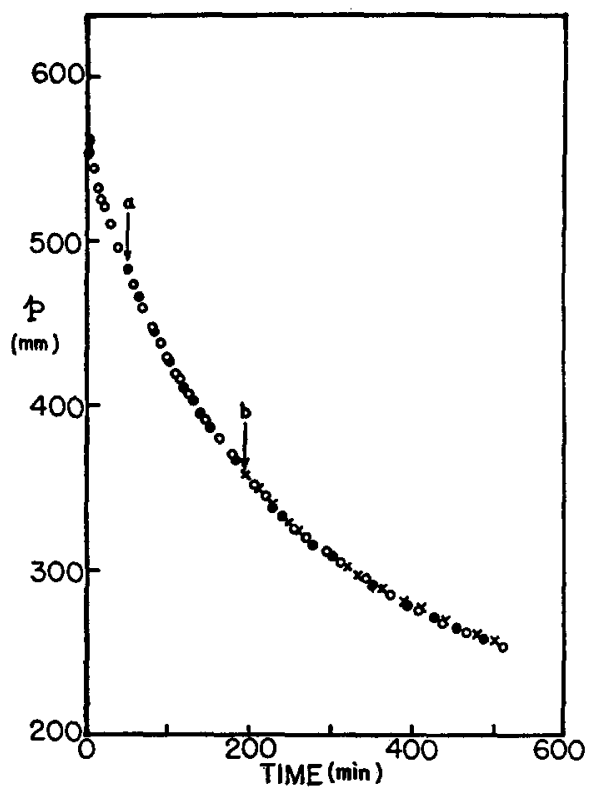

Fig. 4. Plot of total pressure vs time for three stoichiometric runs with different quantities of solid product present. $a$ and $b$ denote start of second and third runs.

of runs with stoichiometric quantities of reactants, at $0.0^{\circ} \mathrm{C},-13.2^{\circ} \mathrm{C}$, and $-23.7^{\circ} \mathrm{C}$. At each temperature, experiments were performed at two different initial pressures, in order to observe any pressure effects on activation energy; no such effects were found. The data are given in Table II. In the last column of this Table the quantity $k_{1}$, defined as the ratio of the second to the third columns, is given. The significance of $k_{1}$ is discussed later in this paper. The activation energy was calculated from the slope of a plot of $\log k_{1}$ against $1 / T$ and found to be $11.4 \pm 2.0 \mathrm{kcal} \mathrm{mole}^{-1}$. The constant $\mathrm{C}$ was taken as temperature independent to a first approximation; the slope was found to be independent of the value of $C$ chosen, and a value of $100 \mathrm{~mm}$ was used as is indicated in Table I.

\section{DISCUSSION}

A mechanism for this reaction must be consistent with a number of experimentally observable phenomena; among these, the effect of the back reaction, the observed pseudo first-order kinetics for each reactant, and the absence of surface effects may be mentioned as of primary importance. A possible mechanism which should be considered involves the preliminary dissociation of diborane into borine radicals:

$$
\begin{gathered}
\mathrm{B}_{2} \mathrm{H}_{6} \underset{k_{-0}}{\stackrel{k_{0}}{\rightleftharpoons}} 2 \mathrm{BH}_{3} \\
\mathrm{BH}_{3}+\mathrm{PH}_{3} \underset{k_{-2}}{\stackrel{k_{2}}{\rightleftharpoons}} \mathrm{BH}_{3} \mathrm{PH}_{3}(g) \\
\mathrm{BH}_{3} \mathrm{PH}_{3}(g) \underset{k_{-3}}{\stackrel{k_{3}}{\rightleftharpoons}} \mathrm{BH}_{3} \mathrm{PH}_{3}(s) .
\end{gathered}
$$

In order that this kinetic scheme be consistent with the lack of effect of increased surface of solid product on the rate, it would appear to be necessary that the reaction steps involving evaporation and condensation on this surface (the last equation of the above mechanism) be sufficiently rapid so that the concentrations of any intermediates are surface independent and therefore essentially equal to their equilibrium concentrations. This implies that the gas phase concentration of $\mathrm{BH}_{3} \mathrm{PH}_{3}$ will be equal to its equilibrium concentration at all times, and therefore

$$
\left(\mathrm{BH}_{3} \mathrm{PH}_{3}\right)_{s}=k_{-3} / k_{3} \text {. }
$$

The rate equation obtained from this mechanism (making the above assumption) is a complicated function of the reactant concentrations, but its behavior under extreme conditions of high and low phosphine pressure can easily be inferred and its behavior in the intermediate pressure range estimated by interpolation. In this manner it was found that the mechanism is not compatible with the experimental facts.

Another possible mechanism is the following:

$$
\begin{gathered}
\mathrm{B}_{2} \mathrm{H}_{6}+\mathrm{PH}_{3} \underset{k_{-1}}{\stackrel{k_{1}}{\rightleftharpoons}} \mathrm{BH}_{3} \mathrm{PH}_{3}(g)+\mathrm{BH}_{3} \\
\mathrm{BH}_{3}+\mathrm{PH}_{3} \underset{k_{-2}}{\stackrel{k_{2}}{\rightleftharpoons}} \mathrm{BH}_{3} \mathrm{PH}_{3}(\mathrm{~g}) \\
\mathrm{BH}_{3} \mathrm{PH}_{3}(g) \underset{k_{-3}}{\stackrel{k_{3}}{\rightleftharpoons}} \mathrm{BH}_{3} \mathrm{PH}_{3}(s) .
\end{gathered}
$$

It follows from the usual steady-state analysis for $\left(\mathrm{BH}_{3}\right)$ that

$$
\left(\mathrm{BH}_{3}\right)=\frac{k_{1} \mathrm{BP}+k_{-2}\left(\mathrm{BH}_{3} \mathrm{PH}_{3}\right)_{g}}{k_{2} \mathrm{P}+k_{-1}\left(\mathrm{BH}_{3} \mathrm{PH}_{3}\right)_{g}} .
$$

Since the rate of disappearance of diborane is given by

$$
-d \mathrm{~B} / d t=k_{1} \mathrm{BP}-k_{-1}\left(\mathrm{BH}_{3} \mathrm{PH}_{3}\right)_{o}\left(\mathrm{BH}_{3}\right),
$$

it follows that

$$
-\frac{d \mathrm{~B}}{d t}=k_{1} \frac{\mathrm{BP}^{2}-k_{-1} k_{-2}\left(\mathrm{BH}_{3} \mathrm{PH}_{3}\right)_{o}^{2} / k_{1} k_{2}}{\mathrm{P}+k_{-1}\left(\mathrm{BH}_{3} \mathrm{PH}_{3}\right)_{g} / k_{2}} .
$$

With the aid of Eq. (2), and setting $\mathrm{K}_{e}=\mathrm{B}_{\infty} \mathrm{P}_{\infty}{ }^{2}$ $=k_{-1} k_{-2} k_{-3}{ }^{2} / k_{1} k_{2} k_{3}^{2}$, we obtain the rate equation

$$
-d \mathrm{~B} / d t=k_{1}\left(\mathrm{BP}^{2}-\mathrm{K}_{e}\right) /(\mathrm{P}+\mathrm{C})
$$

where $\mathrm{C}=k_{-1} k_{-3} / k_{2} k_{3}$. The rate of total pressure decrease is of course three times that of diborane.

According to this equation, the initial rate will be a linear function of the initial diborane concentration for a given initial phosphine concentration, $\mathrm{P}_{i}$, in agreement with the experimental data. When the initial rate of total pressure decrease is plotted against 
the initial diborane pressure, the slope, according to Eq. (6), is given by

$$
3 k_{1} \mathrm{P}_{i}^{2} /\left(\mathrm{P}_{i}+\mathrm{C}\right) \text {. }
$$

To obtain an approximate, simple relation for the variation of rate with initial phosphine pressure, we first rewrite Eq. (6) as

$$
-\frac{d \mathrm{~B}}{d t}=k_{1} \mathrm{~B}\left[\mathrm{P}-\left(\frac{\mathrm{K}_{e}}{\mathrm{~B}}\right)^{\frac{1}{2}}\right]\left[\mathrm{P}+\left(\mathrm{K}_{e} / \mathrm{B}\right)^{\frac{1}{2}}\right] /(\mathrm{P}+\mathrm{C}) .
$$

At constant initial diborane pressure but at varying $\mathrm{P}_{i}$, the factor $\left[\left(\mathrm{P}+\left(\mathrm{K}_{e} / \mathrm{B}\right)^{\frac{1}{2}}\right] /(\mathrm{P}+\mathrm{C})\right.$ changes relatively little although $\left[\mathrm{P}-\left(\mathrm{K}_{e} / \mathrm{B}\right)^{\frac{1}{2}}\right]$ is varied considerably under the present experimental conditions. Thus, according to this equation, a plot of initial rate of total pressure decrease against initial phosphine pressure should be essentially linear (as observed experimentally), with a slope

$$
3 k_{1} \mathrm{~B}_{i}\left[\langle\mathrm{P}\rangle_{\mathrm{Av}}+\left(\mathrm{K}_{e} / \mathrm{B}_{i}\right)^{\frac{1}{2}}\right] /\left(\langle\mathrm{P}\rangle_{\mathrm{Av}}+\mathrm{C}\right),
$$

where $\langle\mathrm{P}\rangle_{\mathrm{Av}}$ is some suitably averaged initial pressure of phosphine over the pressure range investigated, while $\mathrm{B}_{i}$ is the constant initial diborane pressure.

When the pressure of either reactant is in excess, Eq. (6) simplifies to the first-order equation observed for the rate-time data given in Fig. 2. To show this, it is first observed that Eq. (6) may be written as

$$
\begin{aligned}
-\frac{d \mathrm{~B}}{d t}=k_{1} \frac{\mathrm{BP}^{2}-\mathrm{B}_{\infty} \mathrm{P}_{\infty}{ }^{2}}{\mathrm{P}+\mathrm{C}} & k_{1} \frac{\left(\mathrm{P}^{2}-\mathrm{P}_{\infty}{ }^{2}\right) \mathrm{B}+\mathrm{P}_{\infty}{ }^{2}\left(\mathrm{~B}-\mathrm{B}_{\infty}\right)}{\mathrm{P}+\mathrm{C}}
\end{aligned}
$$

and, therefore, since $\left(\mathrm{B}-\mathrm{B}_{\infty}\right)=\left(\mathrm{P}-\mathrm{P}_{\infty}\right) / 2$

$$
-\frac{d \mathrm{P}}{d t}=k_{1} \frac{2 \mathrm{~B}\left(\mathrm{P}+\mathrm{P}_{\infty}\right)+\mathrm{P}_{\infty}^{2}}{\mathrm{P}+\mathrm{C}}\left(\mathrm{P}-\mathrm{P}_{\infty}\right) .
$$

Inasmuch as the decrease of total pressure is $\frac{3}{2}$ that of the decrease of phosphine pressure, i.e., $p_{t}-p_{\infty}$ $=\frac{3}{2}\left(\mathrm{P}-\mathrm{P}_{\infty}\right)$, it follows that

$$
-\frac{d\left(p_{t}-p_{\infty}\right)}{d t}=k_{1}\left[\frac{2 \mathrm{~B}\left(\mathrm{P}+\mathrm{P}_{\infty}\right)+\mathrm{P}_{\infty}^{2}}{\mathrm{P}+\mathrm{C}}\right]\left(p_{t}-p_{\infty}\right) .
$$

When either reactant is in large excess, the term in brackets varies slowly with time compared with $\left(p_{t}-p_{\infty}\right)$, so that we may write

$$
-\frac{d\left(p_{t}-p_{\infty}\right)}{d t} \cong k\left(p_{t}-p_{\infty}\right)
$$

\begin{tabular}{|c|c|c|c|}
\hline $\begin{array}{l}\text { Temperature } \\
\left({ }^{\circ} \mathrm{C}\right)\end{array}$ & $\begin{array}{c}-\frac{1}{3} \text { rate } \\
\text { (moleliter } \\
\text { min }^{-1} \text { ) }\end{array}$ & $\underset{(\text { moleliter }}{\left(\mathrm{BP}^{-1}\right)^{2}}$ & $\begin{array}{c}k_{1} \\
\underset{\left.\min ^{-1}\right)}{\left(\text { litermole }^{-1}\right.}\end{array}$ \\
\hline 0.0 & $2.11 \times 10^{-5}$ & $1.10 \times 10^{-4}$ & 0.192 \\
\hline-13.2 & 0.62 & 1.18 & 0.053 \\
\hline-23.7 & 0.32 & 1.17 & 0.027 \\
\hline 0.0 & $1.01 \times 10^{-5}$ & $0.52 \times 10^{-4}$ & 0.194 \\
\hline-13.2 & 0.33 & 0.63 & 0.050 \\
\hline-23.7 & 0.017 & 0.62 & 0.027 \\
\hline
\end{tabular}

where $k=k_{1}\left[2\langle\mathrm{~B}\rangle_{\mathrm{Av}}\left(\langle\mathrm{P}\rangle_{\mathrm{Av}}+\mathrm{P}_{\infty}\right)+\mathrm{P}_{\infty}{ }^{2}\right] /\left(\langle\mathrm{P}\rangle_{\mathrm{Av}}+\mathrm{C}\right),\langle\mathrm{B}\rangle_{\mathrm{AV}}$ and $\langle\mathrm{P}\rangle_{\mathrm{Av}}$ denoting suitably averaged values of $\mathrm{B}$ and P. The validity of Eq. (13) is borne out by the plots of Fig. 2.
TABLE II. Experimental data for activation energy.

a $\mathrm{K}_{\theta}$ had a negligible value at the lower temperatures, as determined from data on the dissociation pressure..$^{3} \mathrm{C}$ was taken as equal to $100 \mathrm{~mm}$. The siope of the $\log k_{1} v s 1 / T$ plot was essentially independent of the value of $\mathrm{C}$ selected.

The rate equation may easily be integrated when initial concentrations are stoichiometric; then $\mathrm{P}=2 \mathrm{~B}$ and

$$
-\frac{d \mathrm{P}}{d t}=k_{1} \frac{\mathrm{P}^{3}-\mathrm{P}_{\infty}^{3}}{\mathrm{P}+\mathrm{C}}
$$

which yields on integration

$$
\begin{aligned}
& {\left[\frac{1}{3 \mathrm{P}_{\infty}}-\frac{\mathrm{C}}{3 \mathrm{P}_{\infty}^{2}}\right]\left[\sqrt{3} \tan ^{-1} \frac{2 \mathrm{P}+\mathrm{P}_{\infty}}{\mathrm{P}_{\infty} \sqrt{3}}\right]} \\
& \quad-\left[\frac{1}{3 \mathrm{P}_{\infty}}+\frac{\mathrm{C}}{3 \mathrm{P}_{\infty}^{2}}\right]\left[\frac{1}{\left.-\ln \frac{\mathrm{P}^{3}-\mathrm{P}_{\infty}{ }^{3}}{\left(\mathrm{P}-\mathrm{P}_{\infty}\right)^{3}}\right]}\right]=-k_{1} t+\text { const. }
\end{aligned}
$$

Using the data of Fig. 4, a plot of the left-hand side of this equation against $t$ was found to yield good straight lines for the various values of $\mathrm{C} \mathrm{(0} \mathrm{to} 200 \mathrm{~mm}$ ) which were employed.

\section{EVALUATION OF $k_{1}, \mathrm{C}$, AND THE STERIC FACTOR}

It is, in principle, possible to evaluate $k_{1}$ and $\mathrm{C}$ from either initial-rate or rate $v s$ reaction time data for the formation of the solid product in several ways. For example, $-\left(\frac{1}{3}\right) d p / d t$ may be plotted against $\left(\mathrm{BP}^{2}-\mathrm{K}_{e}\right) /$ $(\mathrm{P}+\mathrm{C})$ for various values of $\mathrm{C}$. The value of $\mathrm{C}$ which yields the best straight line would presumably be the "best" value; the slope of this line would furnish the rate constant $k_{1}$. In practice, it was found that the results of these calculations were quite insensitive to the value of the $\mathrm{C}$ selected, primarily because the function $(\mathrm{P}+\mathrm{C})$ is appreciably less sensitive than $\left(\mathrm{BP}^{2}-\mathrm{K}_{e}\right)$, toward concentration changes. With similar limitations $\mathrm{C}$ could also readily be evaluated by plotting $\left(\mathrm{BP}^{2}-\mathrm{K}_{e}\right) /(-d p / d t)$ vs $\mathrm{P}$. It is seen upon rearranging Eq. (6) that the slope of this plot would be $1 / 3 k_{1}$ while the ratio of intercept to slope would be C. However, it was found that the extrapolation of this plot in order to obtain the intercept was uncertain. Nevertheless, the slope of the plot could quite reliably be estimated. In this manner $k_{1}$ was found to be $8 \times 10^{-6} \mathrm{~mm}^{-1} \mathrm{~min}^{-1}$ at $0^{\circ} \mathrm{C}$.

Another way of estimating these constants would be 
to plot values of $k_{1}$ corresponding to selected values for $\mathrm{C}$, using each set of initial-rate and rate-time data, and to locate the point of intersection of all these plots. Again, it was found that such plots are insensitive to values of $\mathrm{C}$; several intersections were found, lying between $\mathrm{C}=10$ and $\mathrm{C}=100 \mathrm{~mm}$, approximately. The corresponding $k_{1}$ values lay in the much narrower range of 7 to $11 \times 10^{-6} \mathrm{~mm}^{-1} \mathrm{~min}^{-1}$ at $0^{\circ} \mathrm{C}$.

A better approximation should logically be possible by using the data for the rate of dissociation of the solid, $\mathrm{BH}_{3} \mathrm{PH}_{3}$. Here, $\mathrm{P}$ can be very small compared to $\mathrm{C}$ initially, and the function $\left(\mathrm{BP}^{2}-\mathrm{K}_{e}\right) /(\mathrm{P}+\mathrm{C})$ therefore is more sensitive to $\mathrm{C}$. However, it still has to be determined whether the assumptions made in the derivation of $\mathrm{Eq}$. (6) are valid in this region of low pressure.

Using the value $k_{1}=8 \times 10^{-6} \mathrm{~mm}^{-1} \mathrm{~min}^{-1}$, or 2.3 cc mole $\mathrm{sec}^{-1}$, a steric factor $s \cong 3 \times 10^{-5}$ is calculated from the equation

$$
2.3=s \times 10^{14} \exp (-11,400 / \mathrm{RT}),
$$

where $10^{14} \mathrm{cc} \mathrm{mole}^{-1} \mathrm{sec}^{-1}$ is the approximate frequency factor for the bimolecular reactions at $273^{\circ} \mathrm{K}$.

From the point of view of absolute reaction rate theory, one would anticipate that $s$ should have the same order of magnitude as the steric factor for the reaction of ethane with methyl radicals, if the activated complex is "rigid" in both cases; the rotational partition functions of $\mathrm{CH}_{3}$ and $\mathrm{PH}_{3}$ should be roughly similar, likewise those of $\mathrm{C}_{2} \mathrm{H}_{6}$ and $\mathrm{B}_{2} \mathrm{H}_{6}$. The steric factor for the ethane-methyl radical reaction has been reported ${ }^{7}$ as $5 \times 10^{-4}$, in good agreement with our foregoing value when our estimated experimental error of \pm 1.5 orders of magnitude is considered.

${ }^{7}$ Trotman-Dickenson, Birchard, and Steacie, J. Chem. Phys. $19,163(1951)$.

\title{
Self-Diffusion in Liquid Mercury
}

\author{
Norman H. Nachtrieb and Jean Petit \\ Institute for the Study of Metals, The University of Chicago, Chicago, Illinois
}

(Received June 24, 1955)

\begin{abstract}
Self-diffusion in liquid mercury was determined by a shear cell method. At atmospheric pressure, $D=8.5$ $\times 10^{-5} \mathrm{exp}(-1005 / R T) \mathrm{cm}^{2} \mathrm{sec}^{-1}$ from $0^{\circ}$ to $98^{\circ}$. At $30^{\circ}$ for pressures ranging up to $8366 \mathrm{~kg} \mathrm{~cm}^{-2}, \log _{10} D$ $=-0.572 T_{m} / T-4.348$, or $\log _{10} D=-4.7889-9.637 \times 10^{-6} P\left(\mathrm{~kg} \mathrm{~cm}^{-2}\right)$. The activation volume is $0.587 \mathrm{~cm}^{3}$. The pressure dependences of viscosity and diffusivity are identical within experimental error, but the temperature variations are not equal. The results are discussed in terms of an imperfect crystal lattice model of a liquid.
\end{abstract}

A LTHOUGH numerous studies of self-diffusion have been carried out on pure crystalline metals, comparatively little information is available for the liquid state. Diffusion measurements have been reported only for mercury, ${ }^{1,2}$ indium, ${ }^{3}$ lead, ${ }^{4,6}$ and sodium. ${ }^{6,7}$ For the first and last of these metals, the remarkable agreement between the coefficients of viscosity and diffusion provided by the Stokes-Einstein equation deserves closer study. Thus, Hoffman ${ }^{2}$ found the activation energy for self-diffusion in mercury to be $1160 \mathrm{cal} \mathrm{g}^{\mathrm{g}}$ tom $^{-1}$, in fairly close agreement with the activation energy for viscous flow, $1250 \mathrm{cal} \mathrm{g} \mathrm{atom}^{-1}$.*

M. Haissinsky and M. Cottin, J. phys. radium 11, 611 (1950).

2 R. E. Hoffman, J. Chem. Phys. 20, 1567 (1952).

3 Careri, Paolett, and Salvetti, Nuova cimento 11, 399 (1954).

4. Groh and G. von Hevesy, Ann. Physik 63, 85 (1920).

5 L. D. Hall and S. Rothman (private communication).

- R. E. Meyer and N. H. Nachtrieb, J. Chem. Phys. 23, 405 (1955).

${ }_{7}$ R. E. Meyer and N. H. Nachtrieb, J. Chem. Phys. 23, 1851 (1955).

* Calculated from the data of Bingham and Thompson [J. Am. Chem. Soc. 50, 2878 (1928)] from the relation:

$$
\frac{d \log \eta / T}{d(1 / T)}=\Delta H_{v} / R
$$

The value of $r$ calculated from the Stokes-Einstein equation was $0.80 \mathrm{~A}$ which, although low by comparison with either the atomic radius $(1.46 \mathrm{~A})$ or the radius of the divalent ion $(1.12 \mathrm{~A})$, is certainly of the expected order of magnitude. Similarly, Meyer and Nachtrieb ${ }^{7}$ found the activation energy for self-diffusion in liquid sodium to be $2430 \mathrm{cal} \mathrm{g} \mathrm{atom}^{-1}$, in exact agreement with the activation energy for viscous flow calculated from Chiong's precise data. ${ }^{8}$ In that case also, the StokesEinstein radius was $0.93 \mathrm{~A}$, in good agreement with Goldschmidt's ${ }^{9}$ and Pauling' $\mathrm{s}^{10}$ radii for the sodium ion (0.98 A and $0.95 \mathrm{~A}$, respectively).

The agreement in radii is unexpectedly close, since the Stokes-Einstein equation is derived from the assumption of a homogeneous fluid, a postulate which is not at all well fulfilled by a hard sphere model of a monatomic liquid. If, nevertheless, the viscosity and diffusion data conform to such a relationship, one might argue that conduction electrons so effectively

${ }^{8}$ Y. S. Chiong, Proc. Roy. Soc. (London) A157, 264 (1936).

- V. Goldschmidt, Ber. deut. chem. Ges. 60, $1263(1927)$.

${ }^{10}$ L. Pauling, J. Am. Chem. Soc. 49, 765 (1927). 